\title{
The Recrystallization of Microelectronic Lead-Free Solders
}

\author{
Fei-Yi Hung ${ }^{1, *}$, Truan-Sheng Lui ${ }^{2}, *$ Li-Hui Chen ${ }^{2}$ and Zhi-Feng Gu${ }^{2}$ \\ ${ }^{1}$ Institute of Nanotechnology and Microsystems Engineering, Center for Micro/Nano Science and Technology, \\ National Cheng Kung University, Tainan, Taiwan 701, R.O.China \\ ${ }^{2}$ Department of Materials Science and Engineering, National Cheng Kung University, Tainan, Taiwan 701, R.O.China
}

In Sn-2 mass \% Ag- 0.5 mass \%Cu solder alloy, recrystallization was induced by thermal cycles and the homogenized effect of thermal aging promoted the vibration resistance. Due to the inner stress induced by thermal cycles, the thermal cycle specimen not only possessed a finer structure but also a large number of grain boundaries that were able to increase the vibration life. During vibration, dynamic recrystallization (DRX) was able to occur. In addition, DRX and grain growth had an obvious tendency to increase as the tensile strain rate was increased in the Sn-1 mass \%Ag- 0.5 mass $\%$ Cu solder alloy with a high $\beta$-Sn content. Also, high temperatures and plastic deformation had a significant influence on the recrystallization of the solders. [doi:10.2320/matertrans.MRA2008048]

(Received February 8, 2008; Accepted July 22, 2008; Published September 25, 2008)

Keywords: recrystallization, lead-free solder

\section{Introduction}

The interface reliability of lead free solders is being investigated continuously. ${ }^{1-6)}$ Notably, when the interface layer is undamaged during reliability testing, cracks or strain energy will propagate into the bulk solders. So, studying the fracture mechanism of the solder itself is of great importance.

According to relevant reports, ${ }^{7-14)}$ many engineering alloys experience dynamic recrystallization (DRX) during plastic deformation. Some finer recrystallized grains are able to grow at room temperature because of the residual strain heat. If a specimen is subjected to high temperatures, unusually large grains can be observed after DRX. This affects the high temperature deformation resistance of materials. In fact, some solder alloys also possess recrystallized characteristics. Due to the solder not being a structural material, its recrystallization has still not been examined, especially under thermal cycle testing and vibration testing.

J. Zhao ${ }^{14)}$ reported that fatigue cracks in $95 \mathrm{~Pb}-\mathrm{Sn}$ alloy propagated with DRX under different strain rates. Studies of lead free solders, have shown that the mechanical properties of $\mathrm{SAC}^{15-17)}$ and $\mathrm{SZ}^{18-20)}$ are closely related to the cooling rate, aging treatment, element addition, etc. However, recrystallization should not be overlooked. Also, the Ag content in related SAC studies ${ }^{1-3,15-17)}$ has been limited to the range 3.5 4.5 mass \%; low Ag solders ( $<3.5$ mass $\%$ ) have still not been examined. Notably, Fulong $\mathrm{Zhu}^{21)}$ reported the dynamic recovery characteristics of $\mathrm{Sn}-0.7 \mathrm{Cu}-$ $\mathrm{Ni}$ solders (compared with the traditional $\mathrm{Sn} 63 / \mathrm{Pb} 37$ alloy; $\mathrm{Sn}-0.7 \mathrm{Cu}-\mathrm{Ni}$ alloy is not a common solder alloy), revealing that recrystallization is worthy of research. According to the above, recrystallization is closely related to the microstructural characteristics and reliability of the solder, so this study uses low Ag content solders not only to analyze the effect of thermal cycles, but also to investigate the recrystallization mechanism under vibration testing and tensile testing.

*Corresponding author, E-mail: fyhung@mail.mse.ncku.edu.tw; z7408020@email.ncku.edu.tw

\section{Experimental Method}

For the casting process, Sn-2 mass $\%$ Ag- 0.5 mass $\% \mathrm{Cu}$ (SAC205) and Sn-1 mass\%Ag-0.5 mass\%Cu (SAC105) solders were remelted $\left(320^{\circ} \mathrm{C}\right)$ and cast into a Y-shaped copper mold at $200^{\circ} \mathrm{C}$ (designated as AC). In addition, a comparison of vibration data was performed on the thermal cycle specimens and the oil-silicon heat-treatment specimens. The thermal cycle testing was performed from $180^{\circ} \mathrm{C}$ to $25^{\circ} \mathrm{C}$ in a vacuum and each holding duration was controlled at $5 \mathrm{sec}$ for a total of 50 times (TC50). The oil bath conditions were $180^{\circ} \mathrm{C}$ for $1 \mathrm{hr}(\mathrm{H} 1)$ followed by air cooling to room temperature (type of silicon oil: CPC Corporation, Taiwan, heat transfer oil 32B). Hereafter, the specimens will be designated as TC50 and H1.

A simple cantilever beam vibration system was used for the vibration experiments. ${ }^{22)}$ The test specimens, which were rectangular with dimensions $100 \mathrm{~mm} \times 10 \mathrm{~mm} \times 4 \mathrm{~mm}$, were mounted and fixed on end to the vibration shaker. On the vibration frequency vs. the deflection amplitude curve, the maximum deflection amplitude always occurs at the resonant frequency. The resonant frequency is taken as the frequency leading to the largest deflection and is determined by varying the vibration frequency continuously. ${ }^{22)}$ With an aim to understanding the difference in chemical composition of the matrices, the structures of the vibration affected regions were examined using EPMA. For the tensile testing (gauge length section: $20 \mathrm{~mm} \times 4.3 \mathrm{~mm} \times 2.1 \mathrm{~mm}$ ), only SAC105 was selected for investigation of DRX, and three strain rates were selected, namely $7.5 \times 10^{-4} \mathrm{~s}^{-1}$ (R1), $4.2 \times 10^{-3} \mathrm{~s}^{-1}(\mathrm{R} 2)$ and $3.3 \times 10^{-2} \mathrm{~s}^{-1}$ (R3). Each analysis datum was the average of at least $3 \sim 5$ test results.

\section{Results and Discussion}

The microstructure of Sn-2Ag-0.5Cu (SAC205) is shown in Fig. 1(a), with $\beta$-Sn phases and eutectic phases $(\beta$ $\mathrm{Sn}+\mathrm{Ag}_{3} \mathrm{Sn}$ ) distributed in the matrix. Notably, no grain boundary is observed in the dendritic $\beta$-Sn phases (the average grain size of $\beta$-Sn is $42 \mu \mathrm{m}$ ). After thermal cycle 


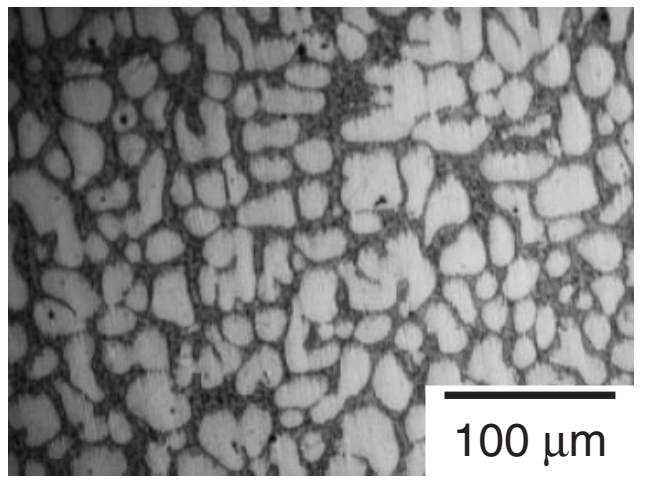

(a)

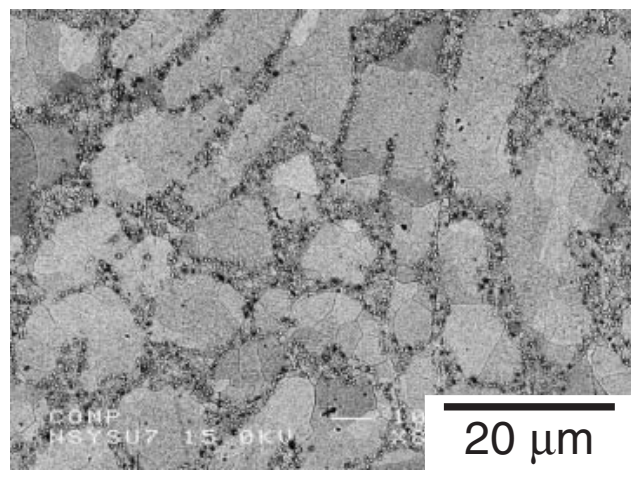

(c)

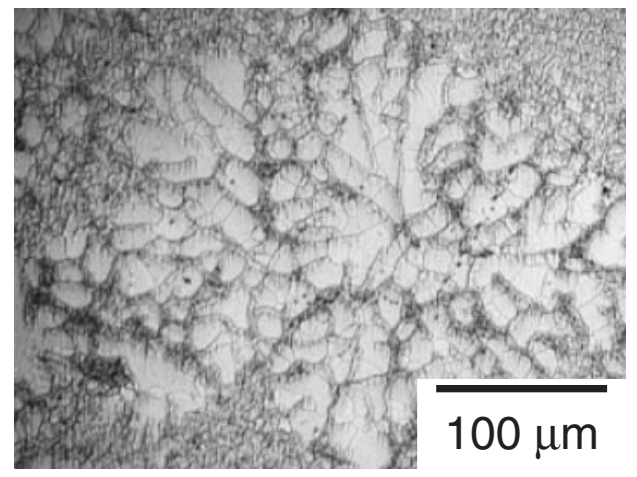

(b)

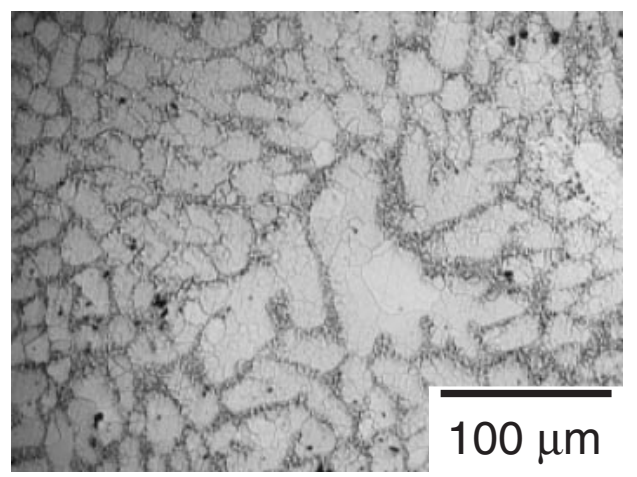

(d)

Fig. 1 SAC205: (a) as-cast (AC), (b) thermal cycles: $180^{\circ} \mathrm{C} \times 50$ cycles (TC50), (c) magnifying image in (b), and (d) oil bath treatment: $180^{\circ} \mathrm{C}-1 \mathrm{~h}(\mathrm{H} 1)$.

testing, $\beta$-Sn phases in the TC50 specimen $\left(180^{\circ} \mathrm{C} /\right.$ $25^{\circ} \mathrm{C} \times 50$ cycles) had become finer and had also experienced recrystallization. Many fine grains were observed in $\beta$-Sns (the average grain size of $\beta$-Sn is $21 \mu \mathrm{m}$ ), even though fine grain of $\beta$-Sn also formed in the eutectic phases, as shown in Fig. 1(b)(c). In fact, the temperature gradient of the thermal cycle from $180^{\circ} \mathrm{C}$ to $25^{\circ} \mathrm{C}$ was very high for the solder.

According to our previous thermoelectric study, ${ }^{23)}$ during the electrical current test, the surface temperature of the solder specimen was $\sim 120^{\circ} \mathrm{C}$. To put it more precisely, the center temperature of the specimen was approximately $\sim 180^{\circ} \mathrm{C}$ (the melting point of $\mathrm{SAC}$ is $\sim 230^{\circ} \mathrm{C}$ ). Under thermal cycle testing, the thermal strain was able to induce lattice distortion and dislocation migration. Based on our previous studies on thermal cycles for cast iron and $\mathrm{Al}$ alloys, ${ }^{24,25)}$ the thermal strain chapped the materials when the number of thermal cycles reached a critical level. Likewise, the temperature gradient in the present experiment was able to result in a small strain field. Under high temperature conditions, this strain energy not only enhanced the diffusion of atoms to the grain boundaries, but also promoted recrystallization. Notably, in Fig. 1(d), recrystallization is observed in both $\beta$-Sn phases and eutectic phases. To clarify the relationship between pure heat and thermal strain, oilsilicon heat-treatment was performed at $180^{\circ} \mathrm{C}$ for $1 \mathrm{hr}(\mathrm{H} 1)$.

Figure 1(d) shows the microstructure of the H1 specimen with the oil-silicon heat-treatment (the average grain size of $\beta$-Sn is $27 \mu \mathrm{m})$. Comparing Fig. 1(d) with the as-cast specimen (Fig. 1(a)), there is an obvious change in the microstructure (refinement of $\beta$-Sn phase: from $42 \mu \mathrm{m}$ to $27 \mu \mathrm{m}$ ), that shows the recrystallization transformation. This indicates that the recrystallization mechanism was not only induced by the strain of thermal cycles, but was also caused by thermal aging. In other words, recrystallization occurred when the temperature of thermal aging was greater than the recrystallized temperature under non-equilibrium solidification conditions. According to data, ${ }^{26)}$ the coefficient of thermal expansion (CTE) of $\mathrm{Sn}$ is larger than that of $\mathrm{Ag}$ and $\mathrm{Cu}$. When the matrix had enough energy for lattice distortion and dislocation migration, static recrystallization and dynamic recrystallization (DRX) were induced. Notably, recrystallization was found in both the $\beta$-Sn phases and the eutectic phases, so it is worth investigating how recrystallization affects the vibrational reliability.

The above specimens underwent vibration fracture testing under constant initial deflection conditions (the resonant frequencies of the specimens did not change with variations in the matrix, and the values were $49 \pm 1 \mathrm{~Hz}$ ). ${ }^{22)}$ The D-N curves of the SAC205 specimens are shown in Fig. 2. (the SAC 205 specimen possessed a better vibration resistance than the SAC105 specimens, Fig. 3) The TC50 specimen showed the greatest vibration life, followed by the $\mathrm{H} 1$ specimen and the AC specimen. It is clear that recrystallization is able to improve the vibration resistance at room temperature. Due to the inner stress induced by thermal cycles, the TC50 specimen not only possessed a finer structure but also a large number of grain boundaries that 


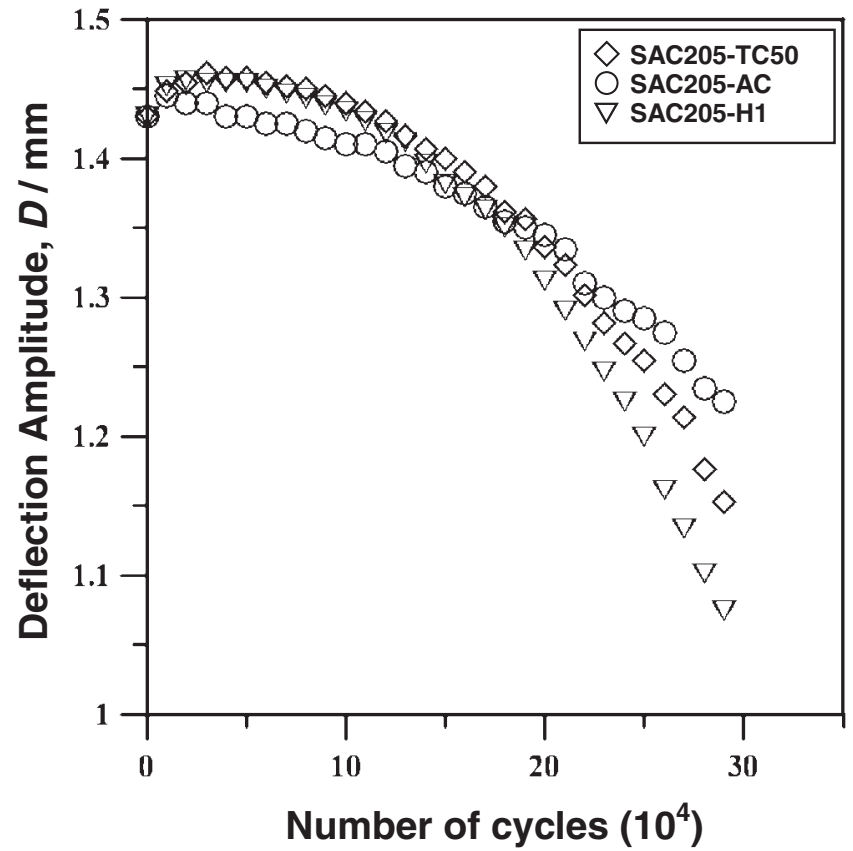

Fig. 2 D-N curves of SAC205 specimens under vibration.

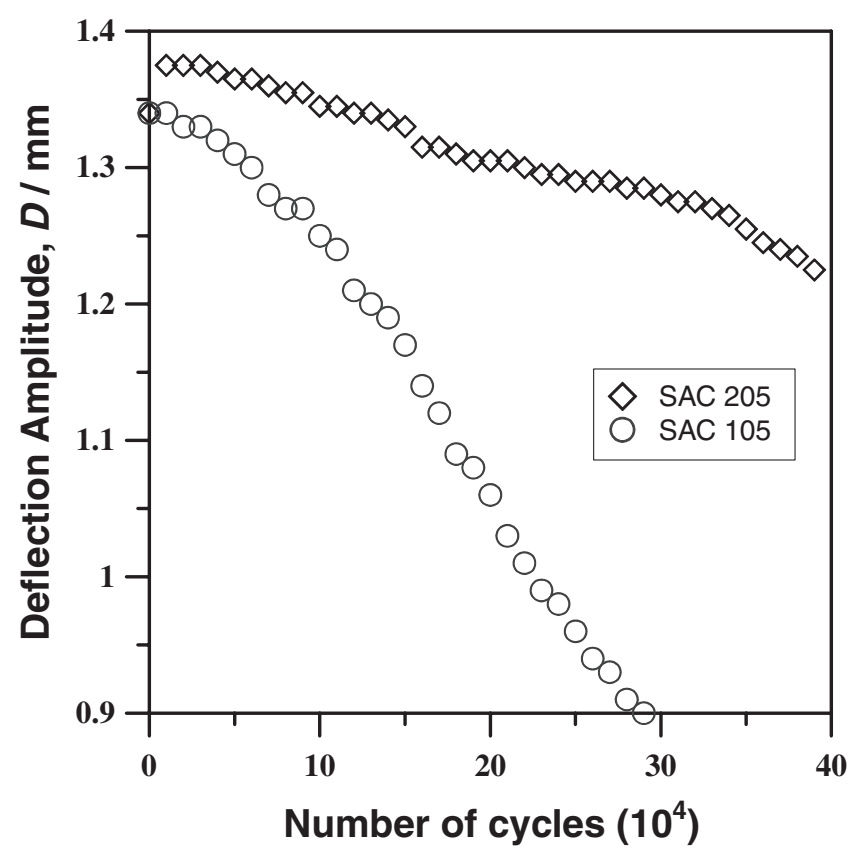

Fig. 3 D-N curves of SAC205-AC and SAC105-AC.

were able to increase the crack tortuosity, which in turn increased the crack propagation resistance and the vibration life. Compared with the AC specimen, the $1 \mathrm{H}$ specimen (pure heat treatment) had a homogenized effect and experienced static recrystallization. Although some $\beta$-Sn phases had grown, the boundary energy still made a great contribution to vibration fracturing.

For many engineering materials, the vibration fracture resistance increases with increasing the tensile deforma tion resistance and Young's modulus of the material in question. ${ }^{27,28)}$ However, this is not true for all materials. ${ }^{29,30)}$ The most likely explanation for this is that vibration testing not only involves fatigue, but also involves a vibration force

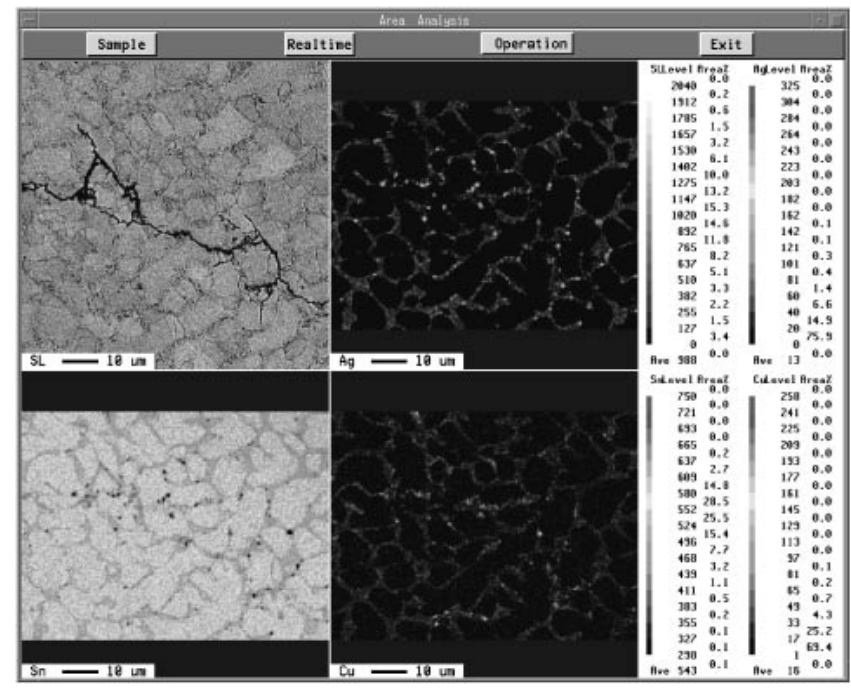

(a)

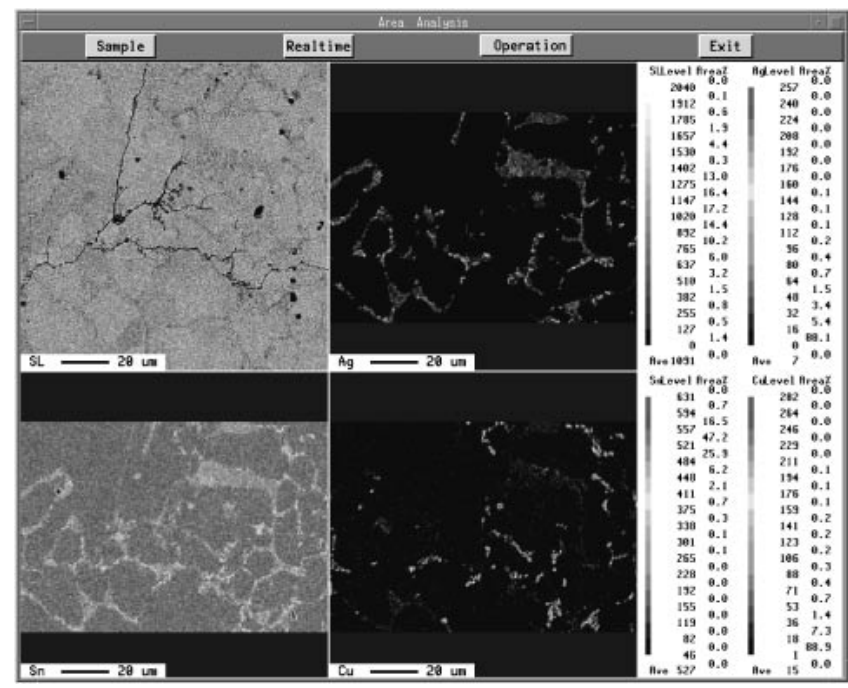

(b)

Fig. 4 EPMA of vibration specimen: (a) SAC205 and (b) SAC105.

with a frequency of $\sim 10^{2} \mathrm{~Hz}$, unlike tensile testing which has a strain rate of $\sim 10^{-3} \mathrm{~s}^{-1}$. Although the present solders had different structures, the $\beta$-Sn phases were probably the main mechanism of DRX, which lengthened the vibration life. In addition, $\beta$-Sn phase had a tendency to increase in the lower $\mathrm{Ag}$ specimens, however the SAC105 specimen had lower vibration resistance than the SAC 205 specimen (Fig. 3).

To obtain the distribution of elements, EPMA analysis of the SAC205 and SAC 105 structures was performed after vibration testing (Fig. 4). Comparing Fig. 4(a) and Fig. 4(b), we find that the vibration crack propagation of the SAC105 specimen showed little tortuosity, however that of the SAC205 specimen exhibited more tortuosity. In other words, the SAC205 possessed finer structures that were able to increase the vibration crack tortuosity, which in turn increased the crack propagation resistance. Notably, the results also revealed that DRX of $\beta$-Sn phases (near vibration cracks) in the low Ag specimen was able to restrain the vibration crack propagation. To understand how DRX occurred without fatigue strain, the DRX of the Sn- 


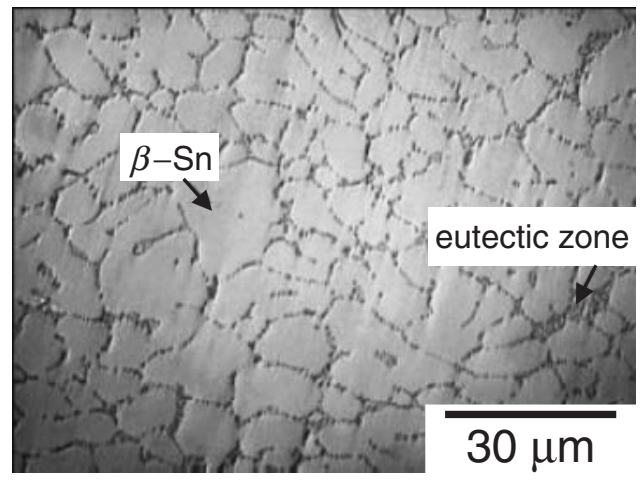

(a)

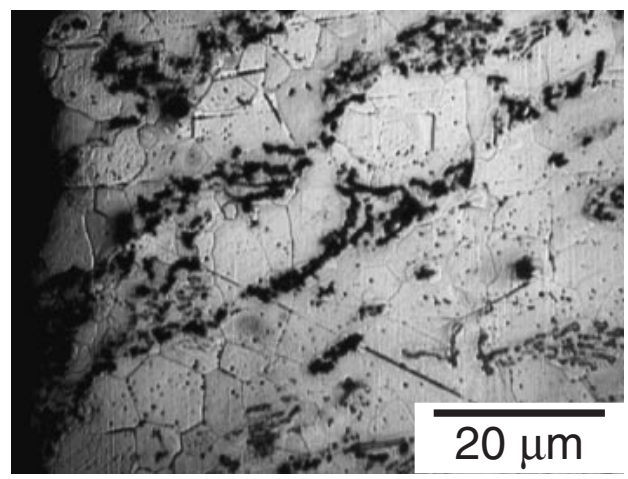

(c)

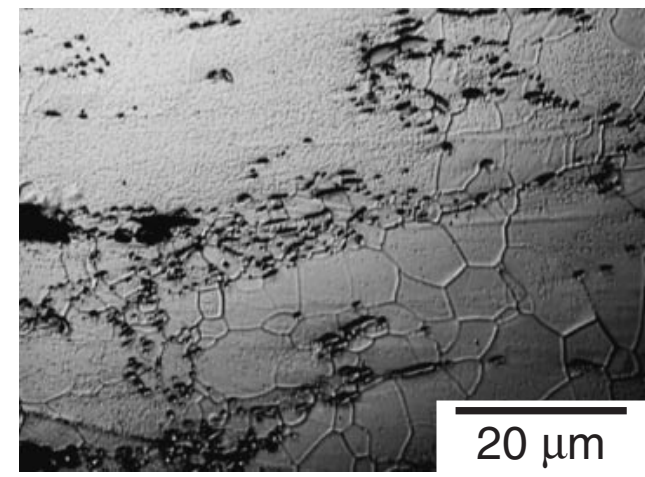

(b)

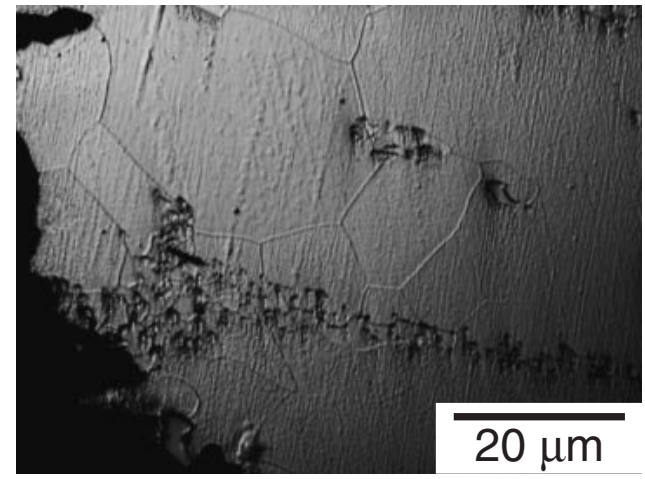

(d)

Fig. 5 The tensile fracture subsurface of the SAC105 specimens with varying strain rates: (a) before test, (b) R1, (c) R2 and (d) R3. (horizontal direction is the tensile direction)

1 mass \% Ag-0.5 mass\%Cu (SAC105) specimen was investigated at different tensile strain rates.

Figure 5 shows a comparison of the tensile fracture subsurface of the specimens with varying strain rates at room temperature, and the fracture characteristics show that the $\beta$-Sn phase had undergone DRX while no DRX was observed in the eutectic zones, thus the $\beta$-Sn phase was the main deformation mechanism. The microstructure of SAC105-AC before test is shown in Fig. 5(a). For the lower strain rate specimen (Fig. 5(b)), DRX only occurred in some $\beta$-Sn phases. According to observations, the area of DRX and the grain size of DRX on the tensile fracture subsurface had an obvious tendency to increase as the strain rate was increased (Fig. 5(c)(d)). In other words, the strain energy not only induced DRX, but also promoted grain growth.

According to our previous study for $\mathrm{Sn}-\mathrm{xCu}$ solders, ${ }^{31)}$ DRX behavior was not observed when the $\mathrm{Cu}$ content was less than 1 mass \%. Comparing $\mathrm{Sn}-\mathrm{Cu}$ solders with the present SAC solders, the results show that increasing the content of solute atoms to more than 1 mass\% in Sn-matrix, not only makes the structures finer, but also leads to obvious DRX after deformation testing and thermal testing. In addition, comparing Fig. 5 with Fig. 1, it is clear that the $\mathrm{Sn}-\mathrm{Ag}-\mathrm{Cu}$ alloys underwent static recrystallization and dynamic recrystallization (DRX). Despite the presence of persistent stress and an axis strain, DRX was induced and the deformation heat also caused the grain growth of $\beta$-Sn phases. Notably, no recrystallization was found in the eutectic phases during single axis tensile testing, and furthermore the eutectic phases were drawn along the tensile direction (Fig. 5, dark zones). The most likely explanation for this is that the $\beta$-Sn phase was the main recrystallization mechanism. Due to the eutectic phases possessing a higher compositional gradient than the $\beta$-Sn phases, static recrystallization was easily observed under non-equilibrium solidification conditions after thermal testing. Also, high temperature and plastic deformation had a significant influence on the recrystallization of the solders. This is why fracture cracks were found either in the intermetallic compound (IMC) layer or in the bulk solder in reliability tests.

\section{Conclusion}

Thermal cycle testing with the strain energy induced recrystallization in SAC solders and refined the structures. Both static recrystallization and dynamic recrystallization (DRX) were able to increase the vibration fracture resistance. When the tensile rate was increased, DRX of $\beta$-Sn had an obvious tendency to increase, and grains growth evenly was promoted.

\section{Acknowledgements}

The authors are grateful to National Cheng Kung University, the Center for Micro/Nano Science and Technology and the Chinese National Science Council for its financial support (NSC 96-2221-E-006-023-CC3 and NSC 97-2221E-006-018). 


\section{REFERENCES}

1) D. Q. Yu, J. Zhao and L. Wang: J. Alloy. Compd. 366 (2004) 170-175.

2) B. Salam, C. Virseda, H. Da, N. N. Ekere and R. Durairaj: Soldering and Surface Mount Technology 16 (2004) 27-23.

3) I. Shohji, S. Tsunoda, H. Watanabe, T. Asai and M. Nagano: Mater. Trans. 46 (2005) 2737-2744.

4) C. M. L. Wu, C. M. T. Law, D. Q. Yu and L. Wang: J. of Electronic Materials 32 (2003) 63-69.

5) K. Suganuma and Y. Nakamura: J. Japan Inst. Metals 59 (1995) 12991305 (in Japanese).

6) K. Suganuma, S. H. Huh, K. Kim, H. Nakase and Y. Nakamura: Mater. Trans. 42 (2001) 286-291.

7) S. M. Fatemi-Varzaneh, A. Zarei-Hanzaki and H. Beladi: Materials Science and Engineering A 456 (2007) 52-57.

8) J. G. Niu, X. Zhang, Z. M. Zhang and B. C. Li: Journal of Materials Processing Technology 187-188 (2007) 780-782.

9) S. B. Yi, S. Zaefferer and H.-G. Brokmeier: Materials Science and Engineering A 424 (2006) 275-281.

10) H. Q. Sun, Y.-N. Shi, M.-X. Zhang and K. Lu: Acta Mater. 55 (2007) 975-982.

11) W. H. Van Geertruyden, W. Z. Misiolek and P. T. Wang: Materials Science and Engineering A 419 (2006) 105-114.

12) A. L. Etter, T. Baudin, N. Fredj and R. Penelle: Materials Science and Engineering A 445-446 (2007) 94-99.

13) A. R. Chezan and J. Th. M. De Hosson: Materials Science and Engineering A 410-411 (2005) 120-123.

14) J. Zhao, Y. Miyashita and Y. Mutoh: International Journal of Fatigue 22 (2000) 665-673.

15) K. S. Kim, S. H. Huh and K. Suganuma: Materials Science and Engineering A 333 (2002) 106-114.
16) Y. Ding, C. Wang, Y. Tian and M. Li: J. Alloy. Compd. 428 (2007) 274-285.

17) K. S. Kim, S. H. Huh and K. Suganuma: Microelectronics Reliability 43 (2003) 259-267.

18) T.-Chun Hsuan and K.-Lung Lin: Materials Science and Engineering A 456 (2007) 202-209.

19) R. Mayappan, A. B. Ismail, Z. A. Ahmad, T. Ariga and L. B. Hussain: J. Alloy. Compd. 436 (2007) 112-117.

20) Y.-Sun Kim, K.-Soo Kim, C.-Won Hwang and K. Suganuma: J. Alloy. Compd. 352 (2003) 237-245.

21) F. Zhu, H. Zhang, R. Guan and S. Liu: Microelectronic Engineering 84 (2007) 144-150.

22) F. Y. Hung, T. S. Lui, L. H. Chen and C. W. Chen: Mater. Trans. 48 (2007) 3014-3020.

23) F. Y. Hung, Z. R. Wang, S. M. Huang, L. H. Chen and T. S. Lui: J. Alloy. Compd. 420 (2006) 193-198.

24) H. M. Lin, T. S. Lui and L. H. Chen: Mater. Trans. 45 (2004) 569-576.

25) J. M. Song, T. S. Lui, I. H. Kao, L. H. Chen and H. M. Lin: Scripta Mater. 51 (2004) 1159-1163.

26) http://www.engineeringtoolbox.com/thermal-expansion-metals-d_859. html.

27) J. H. Horng, T. S. Lui and L. H. Chen: Int. J. Cast Metals Res. 14 (2001) 121.

28) S. C. Lin, T. S. Lui, L. H. Chen and J. M. Song: Metall. Mater. Trans. A 33 A (2002) 2623.

29) F. Y. Hung and T. S. Lui: J. of Mat. Sci. 40 (2005) 3683-3688.

30) Y. H. Song, T. S. Lui and L. H. Chen: Mater. Trans. 45 (2004) 24632470.

31) F. Y. Hung, T. S. Lui, L. H. Chen and N. T. He: J. Alloy. Compd. 457 (2008) 171-176 